\title{
Tribological Behavior of Copper/MWCNT Nanocomposites Produced by Pulse Electrodeposition
}

\author{
H. GÜL ${ }^{a}$, M. UYSAL ${ }^{b}$ H. AKBUlut ${ }^{b}$ AND A. AlP ${ }^{b}$ \\ ${ }^{a}$ Düzce University, Gumusova Vocational School Department of Metallurgy, 81850, Gumusova, Duzce, Turkey \\ ${ }^{b}$ Sakarya University, Department of Metallurgical and Materials Engineering, 54187, Sakarya, Turkey \\ Copper coatings containing well-distributed multiwalled carbon nanotubes were obtained by pulse electrode- \\ position in acidic sulfate bath in order to improve the microhardness and wear resistance of coatings. Multiwalled \\ carbon nanotubes concentration was determined as the most significant factor for the incorporation of multiwalled \\ carbon nanotubes in copper based electrolyte. The amount of embedded multiwalled carbon nanotubes and the \\ microhardness of nanocomposites were found to increase with the increase of multiwalled carbon nanotubes in the \\ electrolyte. The tribological properties of nanocomposites deposited by pulse electrocodeposition technique were \\ studied by reciprocating ball on-disk method. The characterization of the coatings was investigated by scanning \\ electron microscopy and X-ray diffraction facilities. The experimental results indicated that the wear resistance \\ of copper composite is superior to that of pure copper. The friction coefficient and wear rates decreased with the \\ increase in the concentration of multiwalled carbon nanotubes in the electrolyte.
}

DOI: $10.12693 /$ APhysPolA.125.254

PACS: 81.15.Pq, 78.67.Sc, 81.40.Pq, 61.48.De

\section{Introduction}

The codeposition of solid particles during metal electrodeposition is an attractive method to improve the properties of the coatings material, such as wear resistance, lubrication, or corrosion resistance [1-5]. In order to improve the properties of metal matrix coatings, ceramic particles, metallic or non-metallic compounds, as well as graphite, carbon nanofibers and microcapsules containing lubricants were incorporated into metal matrix [1, 4-6]. Pulse plating provides a unique control over the structure and properties of nanocomposite coatings when compared with the conventional direct current [7-9]. Pulse current electrodepositions have higher mechanical and tribological properties than direct current platings $[8,10]$. Carbon nanotubes (CNTs) show a better combination of electrical, mechanical, thermal, optical and structural properties. Carbon nanotubes (CNTs), in particular, exhibit great advantages as a matrix-reinforcing phase for composite coatings in high wear environments owing to their extremely high strength, stiffness and lubricity [11, 12].

The aim of this study is to develop the microstructure and mechanical properties of $\mathrm{Cu}-$ multiwalled $\mathrm{CNT}$ ( $\mathrm{Cu}-\mathrm{MWCNT})$ coatings. The tribological properties of electrodeposited $\mathrm{Cu}-\mathrm{MWCNT}$ coatings containing functionalized MWCNTs in reciprocating wear are examined and compared to the performance of the pure electrodeposited copper coatings.

\section{Experimental procedure}

The plating electrolyte used for the process was an acidic sulfate type electrolyte. The electrolyte bath is composed with $200 \mathrm{~g} / \mathrm{L} \mathrm{CuSO}{ }_{4} \cdot 6 \mathrm{H}_{2} \mathrm{O}$ and $15 \mathrm{ml} / \mathrm{L}$
$\mathrm{H}_{2} \mathrm{SO}_{4}$. The electrolyte temperature coating was controlled at $30^{\circ} \mathrm{C}( \pm 2)$ and the $\mathrm{pH}$ was fixed at $1( \pm 0.2)$. A copper plate of $30 \mathrm{~mm} \times 35 \mathrm{~mm}$ was used as an anode, and a stationary copper substrate was used as a cathode. The amount of MWCNTs in the electrolyte was studied at $0,0.5,1,2$, and $4 \mathrm{~g} / \mathrm{L}$, respectively. MWCNTs were suspended in the electrolyte, magnetically stirred for $10 \mathrm{~h}$ at $400 \mathrm{rpm}$, ultrasonically agitated for $30 \mathrm{~min}$, and electro co-deposited at peak current density of $50 \mathrm{~mA} / \mathrm{cm}^{2}$ and duty cycle $50 \%\left(T_{\text {on }}: 5 \mathrm{~ms}, T_{\text {off }}: 5 \mathrm{~ms}\right.$, and frequency $100 \mathrm{~Hz}$ ) for $1 \mathrm{~h}$ plating time. The depositions were controlled to obtain the coatings in specific thickness (between 50 and $120 \mu \mathrm{m}$ ).

After co-deposition, a scanning electron microscope (SEM) (JEOL-JSM $6060 \mathrm{LV}$ ) was used to observe the surface and microstructures of the deposits. X-ray diffraction (XRD) analysis was carried out with a Rigaku D/MAX/2200/PC model XRD system scanning at a speed of $1^{\circ} / \mathrm{min}$ in the $2 \theta$ range of $10-100^{\circ}$. The hardness of the coatings was measured using a Vickers microhardness (Leica VMHT) with a load of $50 \mathrm{~g}$ for $15 \mathrm{~s}$. The reciprocating tribological behaviors of the coatings sliding against an M50 steel ball (Ø $10 \mathrm{~mm}$ ) were examined on a Tribometer (CSM Instruments) designed according to DIN 50324 and ASTM G 99-95a in a ball-on-disk configuration. The wear tests were performed at a constant applied load of $1.0 \mathrm{~N}$ with sliding speeds of $100 \mathrm{~mm} / \mathrm{s}$.

\section{Results and discussion}

Increasing the MWCNT content in the electrolyte resulted in increasing the amount of the nanotubes, which were also confirmed by SEM analysis. Figure 1 shows the SEM microstructures of $\mathrm{Cu}-\mathrm{MWCNT}$ composite coatings. The results showed an increment of the CNTs in the deposited $\mathrm{Cu}$ layer by increasing MWCNT content 

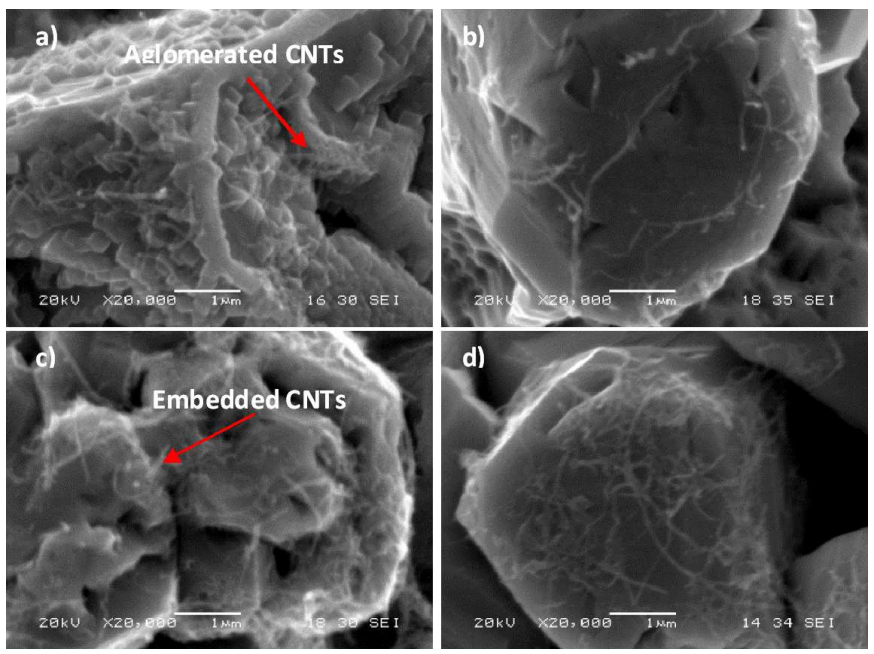

Fig. 1. SEM micrographs of $\mathrm{Cu} / \mathrm{MWCNT}$ composite coatings, produced with different MWCNT content in the electrolyte: (a) $0.5 \mathrm{~g} / \mathrm{L}$, (b) $1 \mathrm{~g} / \mathrm{L}$, (c) $2 \mathrm{~g} / \mathrm{L}$, and (d) $4 \mathrm{~g} / \mathrm{L}$ (arrows show nanotubes).
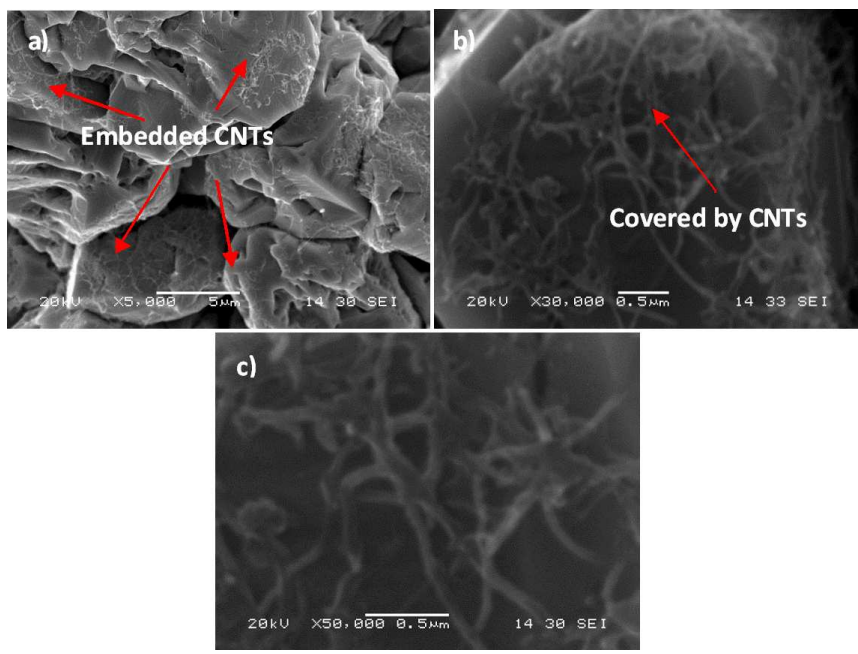

Fig. 2. High magnification SEM micrographs of $\mathrm{Cu} / \mathrm{MWCNT}$ composite coatings, produced with $4 \mathrm{~g} / \mathrm{L}$ MWCNT content in the electrolyte: (a) $5000 \times$, (b) $20000 \times$, and (c) $50000 \times$ (arrows show nanotubes).

in the electrolyte. The amount of embedded CNTs was reached to a maximum value at $4 \mathrm{~g} / \mathrm{L}$ MWCNT content.

Figure 2 shows the distribution of MWCNT in the deposited layer. The volume fraction of co-deposited MWCNTs appeared to increase with the MWCNT content in the electrolyte (Fig. 2). Co-deposition of MWCNTs increased with increasing nanotube content in the plating bath and reached to a maximum value in the $4 \mathrm{~g} / \mathrm{L}$ MWCNTs in the electrolyte. The distribution of MWCNTs reveals more homogeneous distribution when the MWCNT concentration in the electrolyte is increased to $4 \mathrm{~g} / \mathrm{L}$. XRD analysis was used to determine the degree of crystallinity of the phases and the effect of MWCNTs on the preferential growth of copper coating.

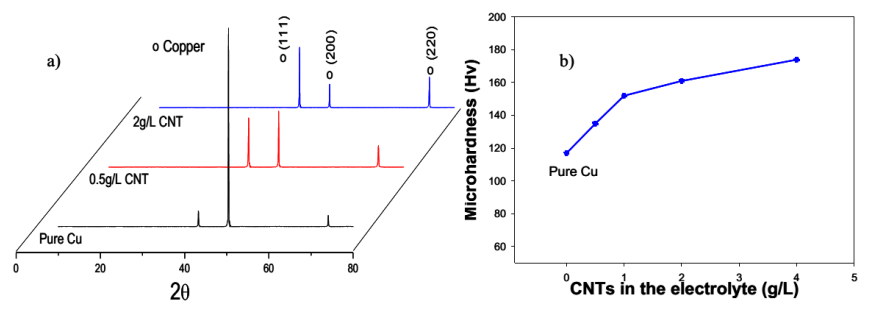

Fig. 3. (a) The XRD patterns and (b) microhardness of pure copper and composite coatings with different CNTs content in the electrolyte.
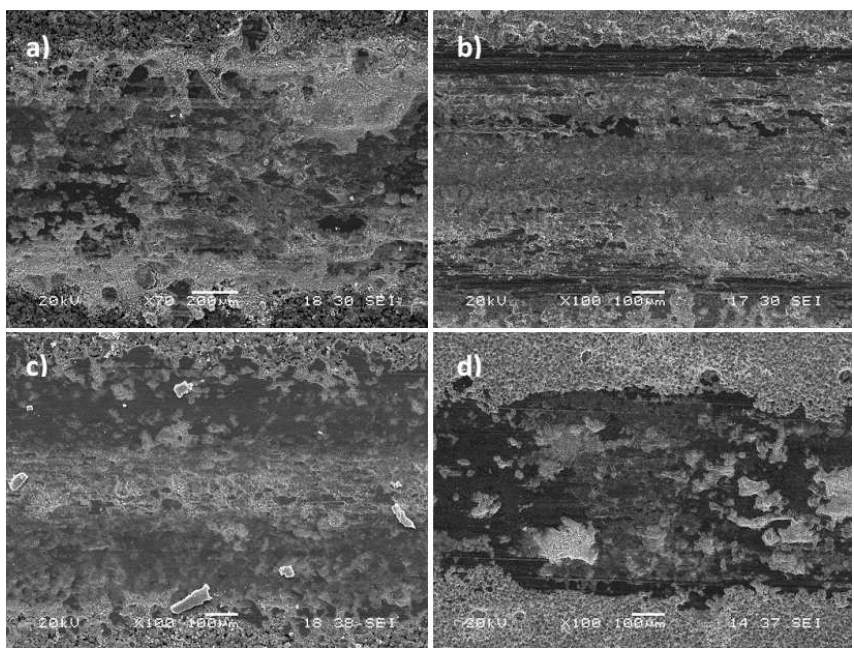

Fig. 4. SEM morphology of the wear tracks of composite coatings prepared with different CNTs content in the electrolyte: (a) $0.5 \mathrm{~g} / \mathrm{L}(70 \times)$, (b) $1 \mathrm{~g} / \mathrm{L}(100 \times)$, (c) $2 \mathrm{~g} / \mathrm{L}(100 \times)$, and $(\mathrm{d}) 4 \mathrm{~g} / \mathrm{L}(100 \times)$.

Figure 3a shows the XRD patterns of pure $\mathrm{Cu}$ and $\mathrm{Cu}^{-}$ MWCNT nanocomposites. The intensity of the diffraction peak of (200) copper in the nanocomposite coating is lower, and the peak width is broader than that of the copper coating. The $\mathrm{Cu}-\mathrm{CNT}$ s nanocomposite has exhibited increasing (111) and (220) diffraction lines with an attenuation of (200) line. This was attributed to the decrease in the grain size of the nanocomposite coating with the addition of nanoparticles in the plating bath. The nanoparticles provided more nucleation sites and retarded crystal growth, resulting in a smaller crystal size for the metal matrix in the composite coating $[4,13]$. Figure $3 \mathrm{~b}$ shows microhardness of pure $\mathrm{Cu}$ and $\mathrm{Cu}-\mathrm{CNTs}$ nanocomposites. The effect of MWCNT content in the electrolyte on hardness of the unreinforced copper coating is found to be great. The microhardness of copper coating layer is found to increase almost linearly with increasing nanotube content in the electrolyte.

When Fig. 4 is seen, it can be observed that in the composites, a mixed mode of adhesive-abrasive wear occurred for all the MWCNTs content in the electrolyte. From the SEM micrographs, it can easily be seen that the 

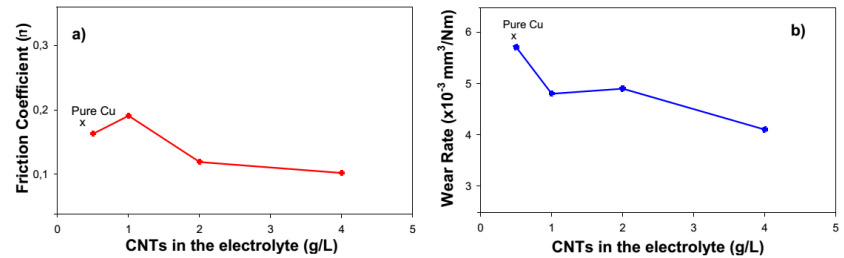

Fig. 5. Effect of the CNTs content in the electrolyte on: (a) friction coefficient of $\mathrm{Cu}-\mathrm{CNTs}$ composite coatings and (b) wear rate of composite coatings.

lowest wear appeared in the sample that was produced at $4 \mathrm{~g} / \mathrm{L}$ MWCNTs content. For the pure $\mathrm{Cu}$ coating the wear track shows identical mechanism with the sample produced with $0.5 \mathrm{~g} / \mathrm{L}$ MWCNTs addition and exhibits a typical adhesive wear and severe delamination along the sliding direction under the combined stresses of compression and shear.

Figure 5a shows effect of MWCNTs content in the electrolyte on friction coefficient wear rate. Increased MWCNT content in the electrolyte caused the decrease in the friction coefficient and wear rate (Fig. 5a and b).

\section{Conclusions}

Copper electro co-depositions, reinforced with MWCNTs were successfully produced by using pulse electrodeposition method. The results revealed that introducing MWCNTs into the electrolyte resulted in increasing the amount of MWCNTs in the copper electrodeposited layer. Increasing MWCNT concentration in the electrolyte revealed more homogeneous distribution of MWNCT in the co-deposited layer up to $4 \mathrm{~g} / \mathrm{L}$ MWCNTs in the electrolyte. Increasing MWCNTs in the electrolyte produced increased microhardness values and improved tribological properties. Increasing MWCNT content in the electrolyte resulted in decrease of both the amount of wear and friction coefficient. These evidenced that introducing MWCNT concentration in the electrolyte up to $4 \mathrm{~g} / \mathrm{L}$ yielded superior load bearing and lubricity in the copper matrix MWCNT reinforced nanocomposites.

\section{References}

[1] A. Robin, J.C.P. Santana, A.F. Sartori, Surf. Coat. Technol. 205, 4596 (2011).

[2] A. Hovestad, L.J.J. Janssen, J. Appl. Electrochem. 25, 519 (1995).

[3] M. Musiani, Electrochim. Acta 45, 3397 (2000).

[4] H. Gül, F. Kılıç, S. Aslan, A. Alp, H. Akbulut, Wear 267, 976 (2009).

[5] M.R. Vaezi, S.K. Sadrnezhaad, L. Nikzad, Coll. Surf. A, Physicochem. Eng. Aspects 315, 176 (2008).

[6] S. Arai, M. Endo, Electrochem. Commun. 7, 19 (2005).

[7] M. Lekka, G. Zendron, C. Zanella, A. Lanzutti, L. Fedrizzi, P.L. Bonora, Surf. Coat. Technol. 205, 3438 (2011).

[8] K.A. Kumar, G.P. Kalaignann, V.S. Muralidharan, Ceram. Int. 39, 2827 (2013).

[9] N. Imaz, E. Garcia-Lecina, J.A. Diez, Trans. Inst. Metal Finish. 88, 256 (2010).

[10] T. Song, D.Y. Li, Nanotechnology 17, 65 (2006).

[11] T. Casagrande, G. Lawson, H. Li, J. Wei, A. Adronov, I. Zhitomirsky, Mater. Chem. Phys. 111, 42 (2008).

[12] C.R. Carpenter, P.H. Shipway, Y. Zhu, Wear 271, 2100 (2011).

[13] H. Gül, F. Kılıç, M. Uysal, S. Aslan, A. Alp, H. Akbulut, Appl. Surf. Sci. 258, 4260 (2012). 